\title{
Giant Cervical Condyloma During Pregnancy: A Case Report
}

\author{
Ruben Martínez-Cumplido ${ }^{1^{*}}$, Eduardo Gonzalez-Bosquet ${ }^{1}$
}

\begin{abstract}
Introduction: Giant condyloma of the cervix (GCC) is an uncommon entity that has been poorly characterized in the literature, being even more uncommon during the pregnancy.

Case Presentation: The authors describe a case of GCC in a pregnant woman as well as reviewing the literature on the topic aiming to reach a better understanding of the natural history of this entity. Our patient is a 27-year-old primigravida of Asian origin. The patient has been diagnosed with cervical giant condyloma in a second trimester coitorrhage context.

Conclusion: A conservative treatment of the giant condyloma could be preferable during pregnancy, carrying surgical excision out after birth.

Keywords: Giant condyloma, Papilloma virus, Pregnancy
\end{abstract}

\section{Introduction}

Human papilloma virus (HPV) infection of the cervix manifests in a variety of morphologic alterations of the epithelium, both squamous and glandular, mature and immature. Although most lesions are flat, some have an exophytic growth with acanthosis and hyperkeratosis and verrucous architecture. Giant condyloma of the cervix (GCC) arises from the confluences of multiple condyloma acuminate. HPV serotypes 6 and 11 represent the most commonly found and their lesions displays absent or weak p16 expression by immunohistochemistry $(1,2)$.

The most common risk factors associated with HPV are: diabetes, low socioeconomic status, smoking, oral contraception, drug abuse, immunosuppression, and other venereal diseases. However it is been noted that HPV rates are highly detected among pregnant women, relating this fact to the alteration in the immune response during pregnancy (2-4).

Patients who present this entity are usually young, presenting vaginal bleeding and/or mass effect. Biopsy reveals a uniformly bland, exophytic squamous epithelial proliferation with viral cytopathic changes and absence of stromal invasion (1).

\section{Case Presentation}

The patient is a 27-year-old primigravida of Chinese origin without a relevant medical record. However, in her gynecological and obstetric record it is noted that she is a primigravida with a history of vulvar condyloma, which was treated successfully topically one year prior to this pregnancy. She presents with regular cycles and started sexual intercourse at 19 years. She had 3 sexual partners and used oral contraception for 18 months prior to the pregnancy. The patient presented to our hospital at 18 weeks of pregnancy with coitorrhage and no further symptomatology. Speculum examination showed a $3 \times 2 \times 3$ $\mathrm{cm}$ exophytic lesion at the upper cervical lip that partially occupied the external cervical orifice without active bleeding (Figure 1).

Cervicovaginal cytology, cervical biopsy and genotyping of HPV by polymerase chain reaction (PCR) were performed. The patient follow-up was done by the cervical pathology unit. The results included a low-degree intraepithelial lesion in the cytology, a positive PCR for serotype 6 and condyloma acuminatum in the histological study of the biopsy.

Given the patient current pregnancy status and the size of the condyloma, we advised the patient to postpone any surgical intervention for fear of cervical bleeding that may endanger the patient's pregnancy, performing a cesarean section because of the risk of neonatal infection in a vaginal delivery.

At postpartum control, 30 days after delivery, a significant decrease in the lesion was observed (Figure 2) and a surgical excision of the condyloma was successfully carried out by diathermic loop. The pathology report showed a low-degree squamous intraepithelial lesion, condyloma.

\section{Discussion}

The giant condyloma from ano-genital region was described by Abraham Buschke and Ludwig Lowenstein in 1896. It was later named Buschke-Lowenstein tumor (BLT) after them. Multiple cases in anus, penis and perineum have been reported since then, being very rarely 


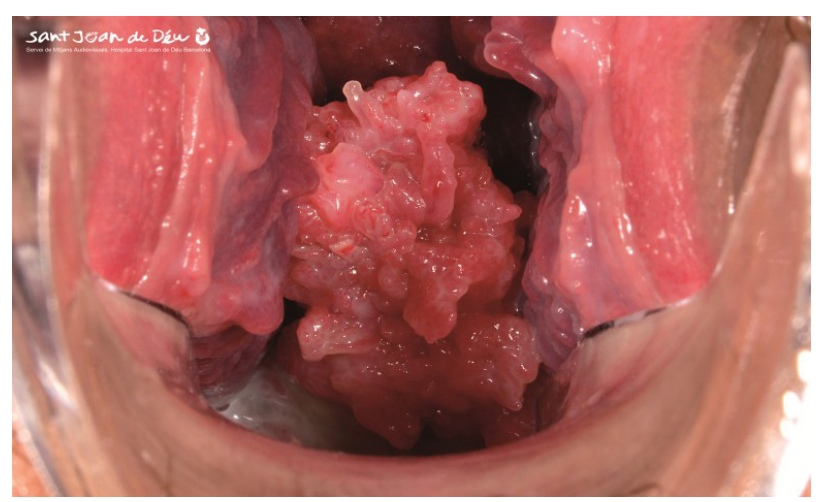

Figure 1. Speculum examination showing an exophytic lesion at the upper cervical lip partially occupying the external cervical orifice without active bleeding. The features of the camera were: Nikon D800E; 60 mm Lens; 125 Shutter speed; f-29; ISO 100; Flash ring.

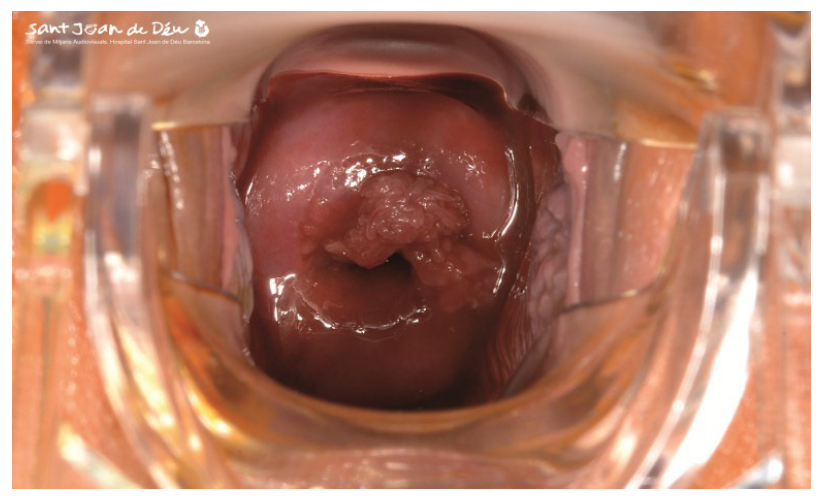

Figure 2. A significant decrease in the lesion was observed. The features of the camera were: Nikon D800E; 60mm Lens; 125 Shutter speed; f-29; ISO 100; Flash ring.

present in the cervix (5).

Condyloma acuminate are frequently located on the external genitalia and perineal zone. They tend to increase and spread after any alteration of the immune system. Condyloma acuminate tend to spread and proliferate quickly during pregnancy and then decrease during puerperium (6). It is known the most risk factors of HPV infection in the literature are diabetes, low socioeconomic status, multiple sexual partners, smoking, oral contraception, drug abuse, immunosuppression, and other veneral diseases $(2,3)$. In our case, the risk factors were young age, three sexual partners and oral contraception. Although we found the condyloma acuminate in a less frequent location, mainly in the cervix, the clinical course of the lesion corresponded to those described above: proliferation during the pregnancy followed by a spontaneous decrease during puerperium. The cases of a localized lesion of HPV developing into an invasive BLT are scarce $(6,7)$.

Large size condylomata may be treated to prevent obstruction/mass effect in the delivery canal, to prevent newborn infections and the possible progression to preneoplastic or neoplastic lesions (1). Reported cases show that some lesions can increases rapidly in size during the pregnancy producing bleeding and mass effect by mechanical obstruction (8). Therefore, we need to asses every single case individually by considering the risks and benefits of management i.e. not only by the characteristics of the lesion but also the best way of delivery (8). In our case, vaginal bleeding was the reason for seeking medical assistance. It was at the exploration when we could note the partial obstruction of the external cervical orifice $(1,4,6,9)$.

The transmission risk to the fetus and the partner should not be underestimated. The estimated risk of transmission to the partner after sexual intercourse is $66 \%$. The estimated transmission risk from fomites is unknown. On the other hand, fetal transmission risk is estimated at a $20 \%$. The manner of delivery (vaginal or cesarean section) does not seem to influence neonatal infection rate (10). Generally the newborn becomes clear of the HPV infection after the first year of life; the development of HPV lesions after that period is very rare (11).

An important reason for the treatment of these lesions in a pregnant woman is the threat of potential progression to cancer (12). Methods that have been used for the treatment of BLT include immunotherapy, radiotherapy, podophyllin and $\mathrm{CO}_{2}$ laser, but none of them treats the lesion successfully (13). Surgical excision is the treatment with the best results (14-16). Nevertheless, it is important to highlight the possibility of more conservative treatments based on the serotype found in the biopsies, being more conservative in low risk serotypes.

Considering the literature review as well as our experience in this case, the authors conclude that this lesion should be treated, due to its features alongside its risk of malignant progression (12-14). The preferred treatment is surgical excision. Nonetheless, given the natural history of these lesions during the pregnancy (6), a conservative treatment could be preferable, finishing the treatment with a surgical excision after birth.

\section{Ethical Issues}

There is no ethical issue in this paper.

\section{Conflict of Interests}

The authors declare no conflict of interests.

\section{Financial Support}

The researchers received no financial support or grant from any funding agency in the public and commercial sectors.

\section{Acknowledgments}

The authors would like to thank the personnel of the Image and Sound Department of Sant Joan de Déu Hospital for their support and pictures.

\section{References}

1. Parra-Herran C, Herfs M, Doria M, Crum CP, Nucci MR. Giant condyloma of the cervix: an uncommon entity associated with low-risk human papilloma 
virus infection. Am Surg Pathol. 2013;37(2):300-304. doi:10.1097/PAS.0b013e31826d261e.

2. Crespo R, Puig F, Lanzon A, Borell A. BuschkeLowenstein tumor and pregnancy: a case report. Eur J Gynaecol Oncol. 2007;28(4):328-329.

3. Rando RF, Lindheim S, Hasty L, Sedlaeck TV, Woodland M, Eder C. Increased frequency of detection of human papillomavirus deoxyribonucleic acid in exfoliated cells during pregnancy. Am J Obstet Gynecol. 1989;161(1):50-55.

4. Morrison EA, Gammon MD, Goldberg GL, Vermund $\mathrm{SH}$, Burk RD. Pregnancy and cervical infection with human papillomaviruses. Int J Gynaecol Obstet. 1996;54(2):125-130.

5. Chu QD, Vezeridis MP, Libbey NP, Wanebo HJ. Giant condylomaacuminatum (Buschke-Lowenstein tumor) of the anorectal and perianal regions: analysis of 42 cases. DIS Colon Rectum. 1994; 37:950-957.

6. Michiels I, Tjalma WA. The rapid development of a giant condyloma acuminatum (Buschke-Löwenstein tumor) during pregnancy. Acta Obstet Gynecol Scand. 2007;86(6):762-763.

7. Reinchenbach I, Koebele A, Foliguet B, Hatier M, Masutti JP, Landes P. A Buschke and Lowenstein tumor in a female patient (In French). J Gynecol Obstet Biol Reprod. 1995;24(5):491-5.

8. X Kurdoğlu M, Kurdoğlu Z, Ozen S. Giant pedunculated leiomyoma of the vulva in fullterm pregnancy: is spontaneous vaginal delivery possible? Arch Gynecol Obstet. 2011;283(3):673-674. doi:10.1007/s00404-010-1656-1.
9. Malek-Mellouli M, Ben AF, Fatnassi A, Reziga H. Giant condyloma in pregnancy. La Tunisie Medicale. 2013;91(6):422-423.

10. Bandyopadhyay S, Sen S, Majumdar L, Chatterjee R. Human papillomavirus infection among Indian mothers and their infants. Asian Pac J Cancer Prev. 2003;4(3):179-184.

11. Tjalma WA, Arbyn M, Paavonen J, Van Waes TR, Bogers JJ. Prophylactic human papillomavirus vaccines: the beginning of the end of cervical cancer. Int J Gynecol Cancer. 2004;14(5):751-761.

12. Armbruster-Moraes E, Ioshimoto LM, Leao E, Zugaib M. Prevalence of high risk human papillomavirus in the lower tract of Brazilian gravidas. Int J Gynaecol Obstet. 2000;69(3):223-227.

13. Jablonska S. Traditional therapies for the treatment of condylomataacuminata (genital warts). Austr J Dermatol. 1998;39:S2-S4.

14. Frega A, Stenella P, Tinai A, Vecchione A, Marchionni M. Giant condyloma acuminatum or BuschkeLowenstein tumor: review of the literature and report of three cases treated by CO2 laser surgery a longterm follow-up. Anticancer Res. 2002;22(2B):12011204.

15. Renzi A, Giordano P, Renzi G, Landolfi V, Del Genio A, Weiss EG. Buschke-Lowenstein tumor succeful treatment by surgical excision alone: a case report. Surg Innov. 2006;13(1):69-72.

16. Niazy F, Rostami K, Motabar AR. Giant condyloma acuminatum of vulva frustrating challenge. World J Plast Surg. 2015;4(2):159-162.

Copyright ( 2016 The Author(s); This is an open-access article distributed under the terms of the Creative Commons Attribution License (http://creativecommons.org/licenses/by/4.0), which permits unrestricted use, distribution, and reproduction in any medium, provided the original work is properly cited. 